\title{
How Safe are Central Counterparties in Credit Default Swap Markets?*
}

\author{
Mark Paddrik ${ }^{a}$ \\ H. Peyton Young ${ }^{b}$
}

June 27, 2019

\begin{abstract}
We propose a general framework for estimating the vulnerability to default by a central counterparty $(\mathrm{CCP})$ in the credit default swaps market. Unlike conventional stress testing approaches, which estimate the ability of a CCP to withstand nonpayment by its two largest counterparties, we study the direct and indirect effects of nonpayment by members and/or their clients through the full network of exposures. We illustrate the approach for the U.S. credit default swaps market under shocks that are similar in magnitude to the Federal Reserve's stress tests. The analysis indicates that conventional stress testing approaches may underestimate the potential vulnerability of the main CCP for this market.
\end{abstract}

Keywords: Credit default swaps, central counterparties, stress testing, systemic risk, financial networks

\section{JEL Classification Numbers: D85, G01, G17, L14}

*We thank Randall Dodd, Marco Espinosa, Samim Ghamami, Dasol Kim, Bruce Tuckman, Stathis Tompaidis, Julie Vorman, and Bob Wasserman for their valuable comments. Additionally we would like to thank OFR's ETL, Applications Development, Data Services, Legal, and Systems Engineering teams for collecting and organizing the data necessary to make this project possible. Views and opinions expressed are those of the authors and do not necessarily represent official positions or policy of the OFR or the U.S. Department of the Treasury.

${ }^{a}$ Office of Financial Research, U.S. Department of Treasury, Washington DC. 20220, United States; email: Mark.Paddrik@ofr.treasury.gov.

${ }^{b}$ London School of Economics, London WC2A 2AE, United Kingdom; University of Oxford, Oxford OX1 3UQ, United Kingdom; Office of Financial Research, U.S. Department of Treasury, Washington DC. 20220, United States; email: Hobart.Young@ofr.treasury.gov. 
Central counterparties have assumed a key role in clearing over-the-counter derivatives as a result of regulatory reforms since the financial crisis (BCBS and IOSCO (2015)). In a centrally cleared market, parties to a derivatives contract enter into two back-to-back contracts with the central counterparty $(\mathrm{CCP})$ that offset one another. There are several important advantages to this arrangement: it creates greater transparency and standardization of contracts, it offers greater potential for the netting of positions, and it shortens the length of intermediation chains, which in principle can reduce contagion (Evanoff et al. (2006); Cont and Kokholm (2014)). It can also reduce the cost of allowing a primary dealer to default (Calomiris (2009)). A significant disadvantage is that the CCP increases systemic vulnerability by creating a critical counterparty whose default would have widespread consequences. It is therefore crucial to understand whether CCPs can withstand large and sudden shocks to asset values, such as occurred in the crisis of 2007-09 and in the European debt crisis of 2011-12:1

The conventional method for stress testing CCPs is to examine whether they have sufficient funds on hand - in the form of initial margins and default fund contributions - to cover payment delinquencies if their two largest counterparties should fail to meet their clearing obligations, an approach known as 'Cover-2' (CFTC (2016)). Several recent papers have argued that this standard is inadequate, because it considers only the direct impact of the two members' failure to pay, and does not take into account network spillover and contagion effects that can amplify the initial payment shortfalls, or the possibility that more than two members could default (Nahai-Williamson et al. (2013); Cumming and Noss (2013); Heath et al. (2015); Poce et al. (2016); Campbell and Ivanov (2016); Heath et al. (2016)).

We examine this issue for the U.S. market in credit default swaps (CDS) and its principal central counterparty ICE Clear Credit. Our approach differs from the prior literature in several key respects. First, our access to contractual over-the-counter positions data from the Depository Trust \& Clearing Corporation (DTCC) means that we have a large representation of the network of CDS exposures. Second, we model contagion using a variant of the Eisenberg-Noe model (2001) that incorporates behavioral responses to balance sheet stress that can be institution-specific. We then estimate the total payment deficiencies that would result from a given financial shock to the

\footnotetext{
${ }^{1}$ For a further discussion of the effects of central clearing on systemic risk see Zigrand (2010), Pirrong (2014), Garratt and Zimmerman (2015), Domanski et al. (2015), Powell (2016), Garratt and Zimmerman (2017).
} 
system. In particular we consider the impact of shocks that are similar in magnitude to the Federal Reserve's 2015 Comprehensive Capital Analysis and Review (CCAR) global trading book shock, which is specifically designed to subject the financial markets to a severe but plausible market stress. Such a shock triggers a sudden drop in the value of credit instruments, which translates into large and sudden variation margin payments on CDS contracts. Firms that are large net sellers of protection may not be able to meet these variation margin payments, which puts increased stress on their counterparties and can lead to a systemwide cascade of payment delinquencies $2^{2}$

This work makes two contributions to the literature on stress testing and CCP counterparty risk assessment. First, we introduce a stress testing framework that looks beyond the direct set of relationships a CCP has with its members, and incorporates indirect (uncleared) exposures among members and nonmembers, whose default can affect the CCP through network spillover effects. Prior work on this issue has been based on limited knowledge of actual network exposures and a limited set of financial institutions, whereas here we have a comprehensive picture of network exposures between banks, brokers, hedge funds, insurance companies and asset managers. The analysis highlights the extent to which the Cover-2 standard underestimates the impact on the $\mathrm{CCP}$ due to the omission of network spillovers effects. One limitation of this analysis is that we focus specifically on the credit default swaps market; some other studies are based on a more complete portfolio of derivatives positions for a subset of banks where such data is available Heath et al. (2016)).

The second contribution is to introduce a method for estimating the probability that the CCP defaults relative to the probability that the average member defaults, while making minimal assumptions about the degree of correlation among member default rates. This estimate takes account of two distinct effects. First, a sudden and severe credit shock can lead to variation margin payment delinquencies due to liquidity constraints. Second, the shock to asset values may cause one or more parent firms to default on their variation margin payments due to insolvency. We estimate the impact on the CCP of these two effects in combination. We find that, under a shock of similar

\footnotetext{
${ }^{2}$ Poce et al. (2016) study the Italian fixed income market instead of the derivatives market. They apply an exogenous shock to firms' equity, estimate the impact on the assets of their counterparties using a Merton model, and then examine the impact on the CCP for the market in Italian government bonds (Cassa di Compensazione e Garanzia). Unlike the present study they do not have direct knowledge of firms' network exposures, but must impute them. As in our study, however, they find that network contagion effects are substantial and imply a greater risk of CCP default than does the conventional Cover-2 standard.
} 
magnitude to the 2015 CCAR shock, the CCP would be able to withstand defaults due to insolvency by as many as four of its members (though its guarantee fund might be severely depleted). Under shocks of slightly greater magnitude, however, the CCP would be significantly more likely to default than the average member.

\section{The central counterparty waterfall}

A CCP represents a nexus of contracts in which its clearing members net and mutualize their counterparty default risk (Duffie et al. (2015)). Beyond the fees the CCP collects per transaction, the incoming and outgoing payment obligations offset each other due to its matched book. In the event that some payments are not received, the CCP has a series of risk mitigation mechanisms that it can draw on, known as the default waterfall. In this paper we shall focus on the major CCP for the CDS market in the United States, ICE Clear Credit. This is a privately held, for-profit company that cleared more than 97 percent of the notional value of CDS contracts on the date of our study in October of $20143^{3}$

At the time of our study, 30 member firms were empowered (though not required) to clear their CDS contracts through the CCP. Contracts by nonmembers are permitted to cleared, but in such cases there must be a member who acts as intermediary and fully guarantees all payments due from the nonmember client to the CCP. Members' balance sheets are subject to scrutiny by the CCP, they must post initial margin against their contracts according to rigorous criteria established by the CCP, and they must contribute to a common guarantee fund that can be drawn on if some members default on their payments. Indeed, there is a whole series of procedures and safeguards designed to protect the $\mathrm{CCP}$ in case one or more members default. The principal elements of the waterfall structure are shown in Table 1 .

Each member's initial margin is held in a segregated account at the CCP and can only be used to cover losses generated by that member should it default. Clients also post initial margin with the CCP, and any losses they generate (including those in excess of the initial margin) are supposed to be fully covered by the member who acts as guarantor. The guarantee fund is funded solely by the members and is held in a common account to cover losses that exceed initial margins in the

\footnotetext{
${ }^{3}$ The only other CCP in this market is CME Clearing, which in 2014 cleared less than 3 percent of the contracts and has since announced its exit from the market.
} 
Table 1: Principal Elements of the Waterfall Structure of ICE Clear Credit as of December 2014.

\begin{tabular}{lc}
\hline \hline \multicolumn{1}{c}{ Tranche } & Total Amount \\
\hline Initial Margins & $\$ 14.1$ billion \\
\hline Guarantee Fund & $\$ 2.4$ billion \\
\hline CCP Capital & $\$ 50$ million \\
\hline Member Assessments & $\begin{array}{c}\text { Up to } 3 \text { times } \\
\text { nondefaulting members } \\
\text { guarantee fund contributions }\end{array}$ \\
\hline \hline
\end{tabular}

Note: Initial margins and the guarantee fund are made up of U.S. Treasuries and cash (USD, CAD, EUR, GBP, JPY).

Source: SEC EDGAR 10-K Filing.

segregated accounts.

If a member defaults, the CCP auctions the member's portfolio of contracts, or it may transfer the contracts to non-defaulting members at mutually agreed prices. The initial margin (IM) posted by the defaulting member is applied to any losses that result from this process. In particular the IM is applied to the delinquent variation margin (VM) payments plus any further losses that may result from the auction or transfer process. (The latter may take several days to complete and will typically occur in highly stressed market conditions, hence the losses incurred in this novation process may be substantial.) To the extent that the IM is insufficient to cover the losses, the CCP draws on its guarantee fund and the CCP shareholders' capital (see in Table 1). First it taps the defaulting members' guarantee fund contributions, then the CCP shareholder's capital, and finally the remaining guarantee fund contributions of non-defaulting members. If all of these sources are still insufficient, the CCP is empowered to assess the non-defaulting members by up to three times the original amount they contributed to the guarantee fund. Although this assessment power would appear to offer a substantial line of defense, in practice it may not be very helpful (France and $\operatorname{Kahn}(2016))$. The difficulty is that when the guarantee fund is exhausted, many of the members will already be in default and unable to pay the assessments.

\section{The DTCC data and the CCAR shock}

We conduct our analysis using detailed data provided to the Office of Financial Research by the Depository Trust \& Clearing Corporation (DTCC). The data include all CDS transactions reported 
to DTCC in which at least one of the counterparties or the reference entity is a U.S. entity. We have a detailed picture of counterparty exposures for a large segment of the CDS market, including exposures between banks, dealers, hedge funds, asset managers, and insurance companies. These include all single-name and index credit default swaps, both cleared and uncleared. The data includes detailed information about underlying references entities, notional amounts bought and sold, inception and terminations dates, and other terms of contracts. We also use data from Markit to estimate credit spreads for all reference entities in the positions we observe.

We focus on the change in value of each contract, and the resulting VM payment owed to each counterparty, under of the Federal Reserve's 2015 Comprehensive Capital Analysis and Review (CCAR) global trading book shock. This shock prescribes an instantaneous widening of credit spreads for corporate, state, municipal, and sovereign debt according to their rating class (Federal Reserve Board (2016)). The shock is applied to all outstanding positions as of October 6, 2014. Credit spreads are widened by a given percentage that alters the value of the premium and payment legs of CDS contracts that reference various classes of debt (see Table 2). These changes in CDS contract values induce variation margin payment obligations between counterparties $4^{4}$

Table 2: The Impact of the 2015 CCAR Severely Adverse Global Market Trading Shock.

\begin{tabular}{lccccccc}
\hline \hline \multicolumn{7}{c}{ Corporate Credit } \\
\hline \multicolumn{7}{c}{ Advanced Economies } \\
\hline AAA & AA & A & BBB & BB & B & $<$ B or Not Rated \\
\hline Spread Widening (\%) & 130 & 133 & 110 & 202 & 269 & 265 & 265 \\
\hline \multicolumn{7}{c}{ Emerging Markets } \\
\hline AAA & AA & A & BBB & BB & B & $<$ B or Not Rated \\
\hline \hline
\end{tabular}

\begin{tabular}{lccccccc}
\hline \hline \multicolumn{7}{c}{ State } & \& M Mnicipal Credit \\
& AAA & AA & A & BBB & BB & B & $<$ B or Not Rated \\
\hline Spread Widening (bps) & 12 & 17 & 37 & 158 & 236 & 315 & 393 \\
\hline \hline
\end{tabular}

\section{Sovereign \& Supra Credit}

See FRB worksheet: CCAR-2015-Severely-Adverse-Market-Shocks-data.xlsx

Source: Federal Reserve Board (2016)

\footnotetext{
${ }^{4}$ For more detail on the methodology underpinning these computations see Paddrik et al. (2019).
} 
The question this paper examines is how likely it is that the CCP could withstand a shock of approximately this magnitude due to defaults by its members. For this purpose we assume that subsidiaries of the same parent firm are likely to default if and only if the parent defaults. Hence we group the members at the bank holding company (BHC) level and view these 15 firms as the entities that are subject to default (see Table 3) 5 Such a shock implies a widening of credit spreads on the BHCs, from which we can infer the annual default probabilities using the methodology described in Luo (2005). On the target date of the shock the implied default probabilities among the 15 member BHCs ranged from 1.7 percent to 3.5 percent, with an average of 2.5 percent per annum. These numbers are similar to the default probabilities implied by CDS spreads during the financial crisis of 2007-09, as shown in Figure1. In other words the impact of the CCAR shock on the CDS spreads is roughly comparable to what occurred in the recent financial crisis.

Table 3: Members of ICE Clear Credit as of December 2014.

\begin{tabular}{|c|c|c|c|}
\hline \multicolumn{4}{|c|}{ ICE Members } \\
\hline $1 . \mathrm{a}$ & Bank of America, N.A. & $8 . \mathrm{a}$ & HSBC Bank USA, N.A. \\
\hline.$b$ & Merrill Lynch, Pierce, Fenner \& Smith Inc. &.$b$ & HSBC Bank plc \\
\hline c & Merrill Lynch International &.$c$ & HSBC Securities (USA) Inc. \\
\hline 2.a & Barclays Bank PLC & 9.a & JPMorgan Chase Bank, N.A. \\
\hline.$b$ & Barclays Capital Inc. &.$b$ & J.P. Morgan Securities LLC \\
\hline 3.a & BNP Paribas & 10.a & Morgan Stanley Capital Services LLC \\
\hline.$b$ & BNP Paribas Securities Corp. & .b & Morgan Stanley \& Co. LLC \\
\hline 4.a & Citibank N.A. & 11.a & Nomura International PLC \\
\hline.$b$ & Citigroup Global Markets Inc. & .b & Nomura Securities International, Inc. \\
\hline 5.a & Credit Suisse International & 12.a & Société Générale \\
\hline.$b$ & Credit Suisse Securities (USA) LLC &.$b$ & SG Americas Securities, LLC \\
\hline 6.a & Deutsche Bank AG, London Branch & 13.a & The Bank of Nova Scotia \\
\hline.$b$ & Deutsche Bank Securities Inc. & 14.a & UBS AG, London Branch \\
\hline 7.a & Goldman, Sachs \& Co. & .b & UBS Securities LLC \\
\hline.$b$ & Goldman Sachs International & 15.a & Wells Fargo Securities, LLC \\
\hline
\end{tabular}

Note: Members with the same numeric value belong to the same holding company and will be treated as a single defaulting firm in our data set.

Source: ICE Clear Credit

\footnotetext{
${ }^{5}$ This approach is consistent with CFTC Regulation 39.33(a) on the implementation of the Cover-2 standard, which assumes that the two largest BHCs default.
} 
Figure 1: Annual Default Probabilities Implied by CDS Spreads for the 15 BHCs.

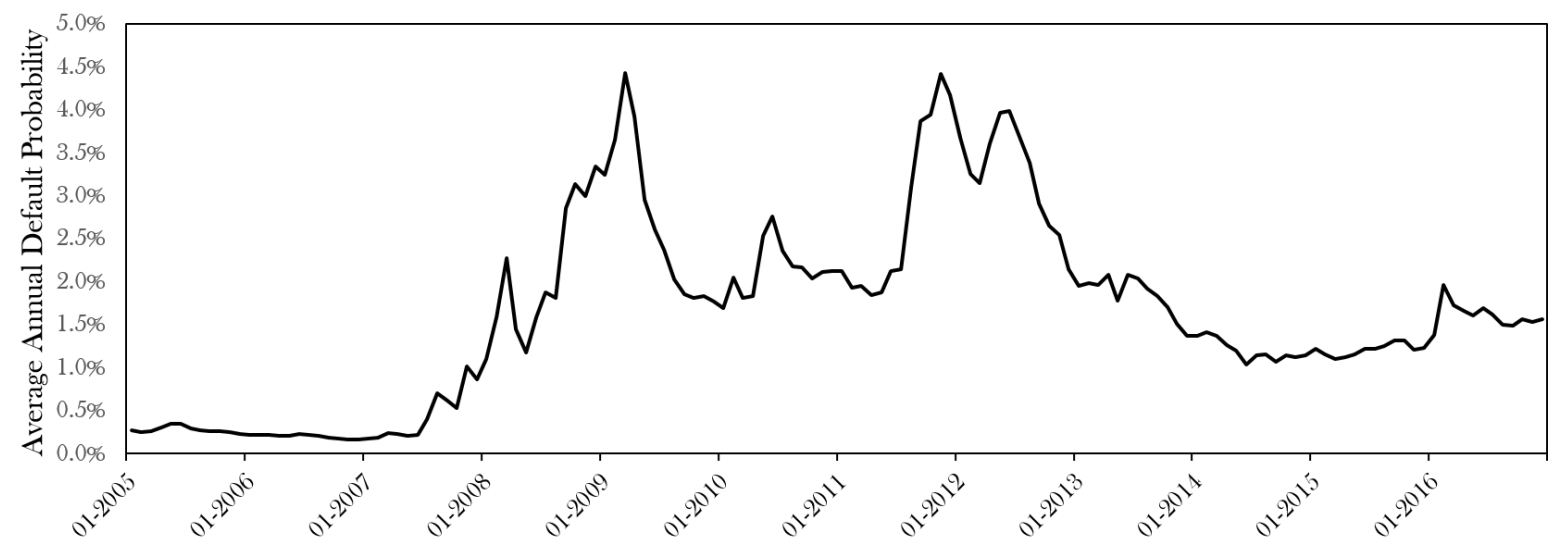

Source: Authors' calculations, which use data provided by Markit Group Ltd.

\section{Conventional risk analysis for the CCP}

The global standard of evaluating potential risk to the CCP is to determine whether it has enough cash or highly liquid assets in its guarantee fund to cover its obligations when two of its members default simultaneously (CFTC (2016); Cont and Minca (2016); Ghamami and Glasserman (2017)). The Cover-2 standard is typically applied to a scenario where the two defaulting members are assumed to be those with the largest net VM obligations to the CCP.

Under the CCAR shock there are eight members that have non-negligible obligations to the CCP. Assuming that any one of them were to default, the IM collected from that member would be sufficient to cover the shortfall except in one case where the guarantee fund would be more than adequate to absorb the remaining shortfall. The same conclusion holds if the two largest members default simultaneously. It would therefore appear that the CCP is well-protected against defaults by its members even in a highly stressed environment.

We argue that this conclusion is overly optimistic, because it does not account for the amplification that can occur through network contagion. The left panel of Figure 2 depicts how conventional stress testing limits the channels of stress to the direct impact of a shock on the CCP. The right panel illustrates how stress can become amplified through the complete network of exposures. We shall show that when two members default simultaneously and network effects are taken into account, there is a non-negligible probability that the CCP's guarantee fund will be insufficient to 
cover delinquent payments by the members. We also argue that the CCP's ability to tap its members for additional assessments will be severely limited for two reasons. First, the funds will be needed in a very short time period (typically a few hours) and the assessments may be contested. Second, many of the members will already be under severe stress and unable to pay the additional assessments.

Figure 2: Network Depiction of CCP Stress Testing

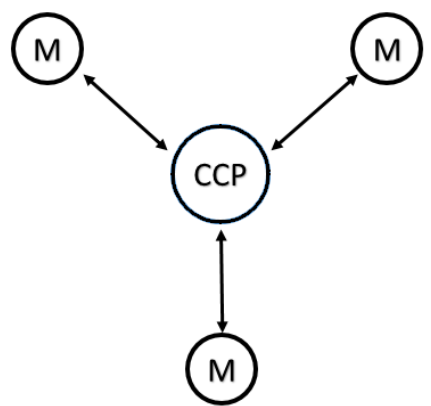

(a) Direct Impact of Shock

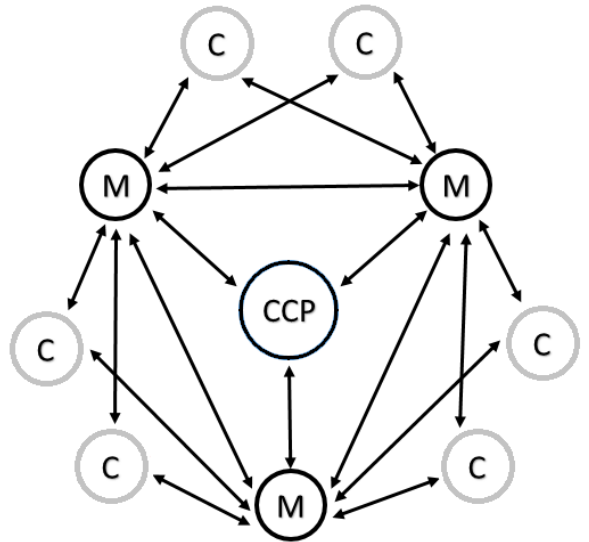

(b) Direct and Indirect Impacts of Shock

Note: M stands for member and C stands for client in the network relationships. Source: Authors' analysis.

\section{The network contagion model}

The network contagion model is a variant of Glasserman and Young (2015), which builds on the benchmark model of Eisenberg and Noe (2001) $]^{6}$ The key contribution of Eisenberg-Noe is to show how to define a consistent set of payments when firms have credit obligations to one another through interlocking balance sheets. If the assets of some firms suffer an exogenous shock, the Eisenberg-Noe framework allows one to compute the extent to which the initial loss in asset values cascades through the system, possibly leading to further defaults.

In the present context, the set-up is somewhat different: an exogenous shock to credit instruments determines the intra-day VM payment obligations between firms on their CDS contracts.

\footnotetext{
${ }^{6}$ A similar model is used in Paddrik, Rajan and Young (2019) to analyze the extent to which the CCP contributes to network contagion.
} 
These payments must be made within a very short time frame. If the VM owed by a given firm exceeds the amount it is owed, the firm experiences short-term stress. This stress can be relieved by drawing on cash and cash equivalents held by the parent institution, but if the stress is large, these funds may be inadequate. In that case, the firm may either pay in part or default completely, depending on its relationship with its counterparties. Thus, the transmission of payment shortfalls is subject to considerable uncertainty, as it depends on the amount of cash available in a firm's treasury. In our model, we shall treat the cash available as a random variable. In this sense, our approach differs from models based on Eisenberg and Noe (2001), which treat default as a deterministic event that is triggered when the default boundary is breached.

We now describe the network model in full. Given a shock to the reference entities on which CDS contracts are written, we shall represent the induced VM payment obligations by a matrix $\left[\bar{p}_{i j}\right]$, where $\bar{p}_{i j}$ is the net amount of VM owed by node $i$ to node $j$ in the aftermath of the shock. (Thus, not both $\bar{p}_{i j}$ and $\bar{p}_{j i}$ are positive because they are bilaterally netted.) If client $i$ 's position with the CCP is guaranteed by member $j$, we represent this in the network as a VM payment from $i$ to $j$ together with an equivalent payment from $j$ to the CCP.

Let $\bar{p}_{i}=\sum_{j \neq i} \bar{p}_{i j}$ be the total payment obligation of $i$ to all other nodes. We shall restrict attention to the nodes $i$ such that $\bar{p}_{i}>0$; the others represent firms that are solely buyers of protection and have no VM obligations. Let $i=0,1,2, \ldots, n$ index the nodes with positive payment obligations and let ' 0 ' represent the CCP. The relative liability of node $i$ to node $j$ is

$$
a_{i j}=\bar{p}_{i j} / \bar{p}_{i}
$$

The relative liability matrix $A=\left(a_{i j}\right)$ is row substochastic, that is for every $i, \sum_{j \neq i} a_{i j} \leq 1$.

For each node $i$, let $c_{k i}$ denote the amount of initial margin $i$ collects from counterparty $k$. The purpose of the IM is to cover possible payment delinquencies. In particular, if counterparty $k$ fails to pay VM to $i$ in a timely manner, the position may be closed out and the IM will be applied to any losses that are incurred between the time of the counterparty's default and the time it takes to close out the position. Alternatively, $i$ may accept partial payment by $k$ and not close out the position, but seize the IM as security until the balance is paid. (Of course this is risky because the value of the contract to $i$ might deteriorate further in the interim.) 
Let $p_{k i} \leq \bar{p}_{k i}$ denote the realized current payment from $k$ to $i$. If $p_{k i}<\bar{p}_{k i}$ the difference will be made up out of the initial margin sitting in $k$ 's account at firm $i$ provided $\bar{p}_{k i}-p_{k i} \leq c_{k i}$. If $\bar{p}_{i k}-p_{k i}>c_{k i}$, then the difference $\bar{p}_{i k}-\left(p_{k i}+c_{k i}\right)$ must be borne by $i$. We define the stress at $i, s_{i}$, to be the amount by which $i$ 's payment obligations exceed the incoming payments from $i$ 's counterparties buttressed by the initial margins, that is,

$$
s_{i}=\left[\sum_{k \neq i} \bar{p}_{i k}-\sum_{k \neq i}\left(\left(p_{k i}+c_{k i}\right) \wedge \bar{p}_{k i}\right)\right]_{+} 7
$$

Note that when all of $i$ 's counterparties pay in full, that is $p_{k i}=\bar{p}_{k i}$ for all $k$, then there is no stress at $i\left(s_{i}=0\right)$.

To complete the model we need to specify how firms respond to balance sheet stress, that is, how much they actually pay their counterparties when they are under stress. The answer depends on a variety of factors, including a firm's cash reserves, its short-term lines of credit, the non-CDS assets on its balance sheet and its relationships with it counterparties. For most firms we do not have enough information to model these factors accurately. Instead we shall adopt a reduced-form approach in which we estimate the expected payments to counterparties as a function of balance sheet stress.

Before describing the approach, however, let us observe that for the CCP itself we do have enough information to model its payments to counterparties under different levels of stress. In particular we know how much liquidity reserves are held in its guarantee fund, which is available to cover residual losses when defaulting members' initial margins are insufficient. We also know that the balance sheet consists entirely of CDS assets, CDS liabilities, and cash reserves; there is no hedging from non-CDS positions. Finally, we know that the CCP is contractually obligated to distribute any losses pro rata among its members (a practice known as variation margin gains haircutting).

The difference between the CCP's VM obligations and the resources it has to meet them is given by the expression

\footnotetext{
${ }^{7}$ In general, $x \wedge y$ denotes the minimum of two real numbers $x$ and $y$, and $[x]_{+}$denotes the non-negative part of $x$.
} 


$$
s_{0}=\left[\sum_{k \neq 0} \bar{p}_{0 k}-\sum_{k \neq 0}\left(\left(p_{k 0}+c_{k 0}\right) \wedge \bar{p}_{k 0}\right)\right]_{+},
$$

where $k$ ranges over the CCP's members. Let $b_{0}$ be the amount in the CCP's guarantee fund. Our assumption is that if $s_{0}>b_{0}$ then the CCP pro-rates the shortfall $s_{0}-b_{0}$ according to the payment obligations to its members, that is,

$$
\forall j, \quad p_{0 j}=\bar{p}_{0 j}-a_{0 j}\left(s_{0}-b_{0}\right)_{+} .
$$

For firms other than the $\mathrm{CCP}$ we shall estimate the expected payment to counterparties using a different approach. Specifically, we shall estimate a transmission factor, $\tau_{i} \geq 0$, such that firm $i$ 's expected shortfall in payments $\bar{p}_{i}-p_{i}$ is proportional to the level of stress $s_{i}$ :

$$
\forall i, \quad \bar{p}_{i}-p_{i}=\tau_{i} s_{i}
$$

Assuming that the shortfall is apportioned among $i$ 's counterparties, we obtain the mapping

$$
\forall i \neq 0, \forall j, \quad p_{i j}=\Phi(p)_{i j}=\left[\bar{p}_{i j}-\tau_{i} a_{i j}\left[\sum_{k \neq i} \bar{p}_{i k}-\sum_{k \neq i}\left(\left(p_{k i}+c_{k i}\right) \wedge \bar{p}_{k i}\right)\right]_{+}\right]_{+} .
$$

The CCP's payments are given by

$$
\forall j, \quad p_{0 j}=\Phi(p)_{0 j}=\left[\bar{p}_{0 j}-a_{0 j}\left[\sum_{k \neq 0} \bar{p}_{0 k}-\sum_{k \neq 0}\left(\left(p_{k 0}+c_{k 0}\right) \wedge \bar{p}_{k 0}\right)-b_{0}\right]_{+}\right]_{+} .
$$

Given values $\bar{p}_{i j}, c_{i j}$, and $\tau_{i}$ for all $i$ and $j$, the function $\Phi(p)$ is order preserving, that is, if $p \leq p^{\prime}$ then $\Phi(p) \leq \Phi\left(p^{\prime}\right)$ in all coordinates. A payment equilibrium, $p^{*}$, is just a fixed point of $\Phi$ : $\Phi\left(p^{*}\right)=p^{*}$. We can compute such a fixed point as follows. Starting with $p^{0}=\bar{p}$, let $p^{1}=\Phi\left(p^{0}\right)$, $p^{2}=\Phi\left(p^{1}\right)$ and so forth. This sequence is monotone decreasing $\left(p^{0} \geq p^{1} \geq p^{2} \geq \ldots\right)$ and is bounded below by the 0 -vector, hence it has a limit $p^{*}$. Since $\Phi$ is continuous, it follows that $\Phi\left(p^{*}\right)=p^{*}$ is a fixed point; moreover it is the greatest fixed point of $\Phi$ (Tarski (1955)). In the empirical sections to follow we shall solve for the greatest fixed point for each specification of our parameters because this provides the most conservative (lowest) estimate of the losses that would 
be triggered by a given shock.

\section{Estimating the transmission factors}

We now describe two approaches to estimating the transmission factors $\tau_{i}$. In the first approach we show how to bound the expected payment shortfall under general conditions on the distribution of the liquidity reserves $b_{i}$, which we treat as a random variable. In the second approach we assume that $b_{i}$ is sufficient to cover net daily outflows of VM with high probability (using the actual daily

fluctuations as reported in the DTCC data). We then compute the payment shortfalls that would arise under a range of shocks that include both more severe and less severe shocks than the CCAR shock. As we shall see, both of these approaches yield estimates of $\tau_{i}$ that lie in the vicinity of one. In the subsequent analysis, we compute the probability of CCP default for values of $\tau_{i}$ that range from between 0.75 and 1.25 , and for a range of shocks sizes that are centered around the CCAR shock, thus providing a check on the robustness of our results.

Let $b_{i}$ denote the size of firm $i$ 's liquid reserves. Then $i$ can pay in full if $b_{i} \geq s_{i}$. If $b_{i}<s_{i}$ we consider two scenarios.

$$
\begin{gathered}
\text { Hard Default: } b_{i}<s_{i} \quad \Rightarrow \quad p_{i}=0 \\
\text { Soft Default: } b_{i}<s_{i} \Rightarrow p_{i}=\bar{p}_{i}-s_{i}+b_{i}
\end{gathered}
$$

Under hard default firm $i$ pays nothing to its counterparties whereas under soft default it pays as much as it can. In practice, the actual behavior of the firm will depend on reputational concerns and its relationship with its counterparties; these are behavioral variables that we do not attempt to model here. Instead we shall use a single value of $\tau$ for all firms that represents an intermediate between the hard and soft default scenarios.

The range of plausible values for $\tau$ can be estimated as follows. First, let us view the buffer $b_{i}$ as the realization of a random variable $B_{i}$. This reflects the fact that the value of $b_{i}$ in a crisis depends on a variety of unknown factors such as the firm's exposure to other assets and its general risk management policies. In the hard default scenario, the expected shortfall in $i$ 's VM payments 
equals

$$
d_{i}=\bar{p}_{i} P\left(b_{i}<s_{i}\right)
$$

We can make a rough estimate of $P\left(b_{i}<s_{i}\right)$ as follows. Since the net amount owed, $\bar{p}_{i}$, arises in a highly stressed environment, it is unlikely that the firm's cash reserves are larger than $\bar{p}_{i}$. Let us therefore assume that the support of $B_{i}$ is $\left[0, \bar{p}_{i}\right]$. Let us further suppose that $B_{i}$ has a density $g_{i}\left(b_{i}\right)$ that is nonincreasing, that is, smaller buffers are at least as likely as larger buffers. It follows that for every realized level of stress $s_{i}$,

$$
\mathrm{P}\left(b_{i}<s_{i}\right) \geq s_{i} / \bar{p}_{i}
$$

Together, 10) and (11) imply

$$
d_{i} \geq s_{i}
$$

that is, the transmission factor $\tau_{i}$ is at least one.

By contrast, in the soft default scenario $i$ 's expected shortfall in payments can be expressed as

$$
d_{i}=E\left[s_{i}-b_{i} \mid b_{i}<s_{i}\right] P\left(b_{i}<s_{i}\right)
$$

Given the preceding assumptions on $g\left(b_{i}\right)$ this leads to an estimated transmission factor $\tau_{i}$ that is less than one.

An alternative approach to estimating the transmission factor is to estimate the liquidity buffers $b_{i}$ directly from the data and then to solve the model under various assumption about the size of the shock and how firms respond to stress. From the DTCC data we can estimate, for each firm $i$, the minimum cash reserves that $i$ would have needed to avoid suffering a shortfall in its CDS payments on any given day in the five years prior to the shock date. Specifically, for each firm $i$, the DTCC data allow us to infer the change in value of $i$ 's CDS contracts on any given day. From this we can deduce the payments due from all of $i$ 's counterparties, as well as the payments due from $i$ to each of its counterparties and hence the net VM payment owed by $i$ on that day. We choose $b_{i}$ to be the smallest value that exceeds the maximum net payment due over the five year 
period prior to October 6, 2014.

We vary the size of the shock by multiplying the VM payment obligations by a scalar $\alpha>0$, where $\alpha=1$ corresponds to the VM payment obligations under the actual CCAR shock. Given a shock of size $\alpha$ on the CCAR shock date, we compute the greatest payment equilibrium under two stress response scenarios: soft default and hard default. In the soft default scenario we find the maximal fixed point of the system

$$
\begin{gathered}
\forall i \neq 0, \forall j, \quad p_{i j}=\Phi(p)_{i j}=\left[\bar{p}_{i j}-a_{i j}\left[\sum_{k \neq i} \bar{p}_{i k}-\sum_{k \neq i}\left(\left(p_{k i}+c_{k i}\right) \wedge \bar{p}_{k i}\right)-b_{i}\right]_{+}\right]_{+}, \\
\forall i, \quad p_{0 j}=\Phi(p)_{0 j}=\left[\bar{p}_{0 j}-a_{0 j}\left[\sum_{k \neq 0} \bar{p}_{0 k}-\sum_{k \neq 0}\left(\left(p_{k 0}+c_{k 0}\right) \wedge \bar{p}_{k 0}\right)-b_{0}\right]_{+}\right]_{+} .
\end{gathered}
$$

Let $p^{*}$ denote this greatest equilibrium. We then compute the total payment deficiency $d^{*}=$ $\sum_{0 \leq i, j \leq n}\left(\bar{p}_{i j}-p_{i j}^{*}\right)$ and the total stress $s_{i}^{*}=\sum_{i=0}^{n} s_{i}^{*}$, where

$$
\forall i, \quad s_{i}^{*}=\left[\sum_{k \neq i} \bar{p}_{i k}-\sum_{k \neq i}\left(\left(p_{k i}^{*}+c_{k i}\right) \wedge \bar{p}_{k i}\right)\right]_{+} .
$$

The ratio

$$
\tau^{*}=d^{*} / s^{*}
$$

is an estimate of the average rate of stress transmission over all nodes in the system in the soft default scenario 8

Similarly, in the hard default scenario, we compute a maximal fixed point of the system

$$
\begin{aligned}
& \forall i \neq 0, \forall j, \quad p_{i j}=\tilde{\Phi}(p)_{i j}=\left\{\begin{array}{cc}
\bar{p}_{i j} & \text { if } \quad \sum_{k \neq i} \bar{p}_{i k} \leq \sum_{k \neq i}\left(\left(p_{k i}+c_{k i}\right) \wedge \bar{p}_{k i}\right)+b_{i} \\
0 & \text { otherwise, }
\end{array}\right. \\
& \forall j, \quad p_{0 j}=\tilde{\Phi}(p)_{0 j}=\left[\bar{p}_{0 j}-a_{0 j}\left[\sum_{k \neq 0} \bar{p}_{0 k}-\sum_{k \neq 0}\left(\left(p_{k 0}+c_{k 0}\right) \wedge \bar{p}_{k 0}\right)-b_{0}\right]_{+}\right]_{+}^{9}
\end{aligned}
$$

\footnotetext{
${ }^{8}$ Alternatively we could estimate the average transmission factor by the expression $(1 / n) \sum_{i=0}^{n}\left(\bar{p}_{i}-p_{i}^{*}\right) / s_{i}^{*}$. It can be shown that this yields a value at least as large as $\tau^{*}$ in $(17)$.
} 
Let $p^{* *}$ denote the greatest equilibrium of this system. As before we compute the total payment deficiency $d^{* *}=\sum_{0 \leq i, j \leq n}\left(\bar{p}_{i j}-p_{i j}^{* *}\right)$ and the total stress $s_{i}^{* *}=\sum_{i=0}^{n} s_{i}^{* *}$, where

$$
\forall i, \quad s_{i}^{* *}=\left[\sum_{k \neq i} \bar{p}_{i k}-\sum_{k \neq i}\left(\left(p_{k i}^{* *}+c_{k i}\right) \wedge \bar{p}_{k i}\right)\right]_{+} .
$$

The estimate of $\tau$ in this case is

$$
\tau^{* *}=d^{* *} / s^{* *}
$$

Table 4 shows the resulting estimates for $\tau$ under a range of $\alpha$-values and hard vs. soft default. In the hard default scenario, the value is somewhat in excess of one, which is consistent with the estimate in (12). As one would expect, the average value of $\tau$ under soft default is smaller (on the order of 0.5-0.7) than it is under hard default. Note that the estimates of $\tau$ are stable over a wide range of shock values. In our view the hard default scenario is more plausible than soft default as a model of short-run response to stress, hence we shall focus on values of $\tau$ that are in a neighborhood of 1 in the empirical sections to follow.

Table 4: Average value of $\tau$ over all firms when liquidity buffers are estimated from the DTCC data.

\begin{tabular}{cccc}
\hline \hline & \multicolumn{3}{c}{$\alpha$} \\
& 0.75 & 1.00 & 1.25 \\
\cline { 2 - 4 } Hard Default: & 1.11 & 1.11 & 1.07 \\
Soft Default: & 0.54 & 0.62 & 0.69 \\
\hline \hline
\end{tabular}

Source: Authors' calculations which use data provided to the OFR by The Depository Trust \& Clearing Corporation and Markit Group Ltd.

\section{Network contagion and its impact on the CCP}

We now apply this framework to evaluate the potential amount of contagion in the CDS market as a function of the shock size $\alpha$ and the average transmission factor $\tau$. Given $\alpha$, we determine

\footnotetext{
${ }^{9}$ We always assume that the CCP engages in variation margin gains haircutting (i.e., soft default) even when all other firms engage in hard default, due to the CCP's contractual obligations to its members. Although $\tilde{\Phi}(p)$ is not continuous in $p$, it is upper semicontinous and monotone decreasing in $p$, hence it has a greatest fixed point (see Paddrik et al. (2019) for details).
} 
the payment vector $\bar{p}$ by widening the credit spreads, as discussed in Section 2 , For each pair of firms $i$ and $j$, we let $c_{i j}$ be the minimum amount that would be sufficient to cover the VM payment due from $i$ to $j$ over a 10-day period with $99.5 \%$ probability. This can be estimated from the distribution of payments that would be due if we held the portfolio of CDS constant and look at its value over the previous 1000 days from the CCAR date, using Markit data. (The 99.5\% VaR level and a 10-day margin period of risk are standard in the industry.) In the interest of simplicity we shall assume a common factor $\tau_{i}=\tau$ for all firms (other than the $\mathrm{CCP}$ ) and examine a range of values for $\tau$ that are in a neighborhood of 1 . This is consistent with the estimates of $\tau$ in the preceding section.

We define the total impact of the shock to be the deficiency in VM payments summed over all nodes in the network. In our notation the total payment deficiency can be expressed as follows

$$
D(\tau, \alpha)=\sum_{i} d_{i}
$$

where $d_{i}=\bar{p}_{i}-p_{i}$ and $\left(p_{0}, \ldots, p_{n}\right)$ is the greatest fixed point of the mapping defined in section 4 . expressions (6) and (7). Figure 3 shows the total deficiency as a fraction of total VM payments owed, $D(\tau, \alpha) / \sum_{i} \bar{p}_{i}(\alpha)$. Note that for each value of $\tau$ this ratio is stable over a wide range of shock values.

The impact of network contagion on the CCP can be measured by the percentage of the guarantee fund that is used to cover members' payment deficiencies. Figure 4 shows the results for $\tau=$ 1.0 and $\tau=0.75$ over a range of shock sizes centered around the CCAR shock $(\alpha=1.0)$. Note that the impact on the CCP is convex and increases sharply for shock sizes slightly greater than 1.0.

The figure also highlights the extent to which a conventional Cover-2 analysis underestimates the impact of a shock on the CCP. This curve (the solid line) shows the percentage of the guarantee fund that is drawn down when the two members with the largest VM obligations fail to pay and no networks effects are considered. 
Figure 3: Payment deficiency relative to total amount owed.

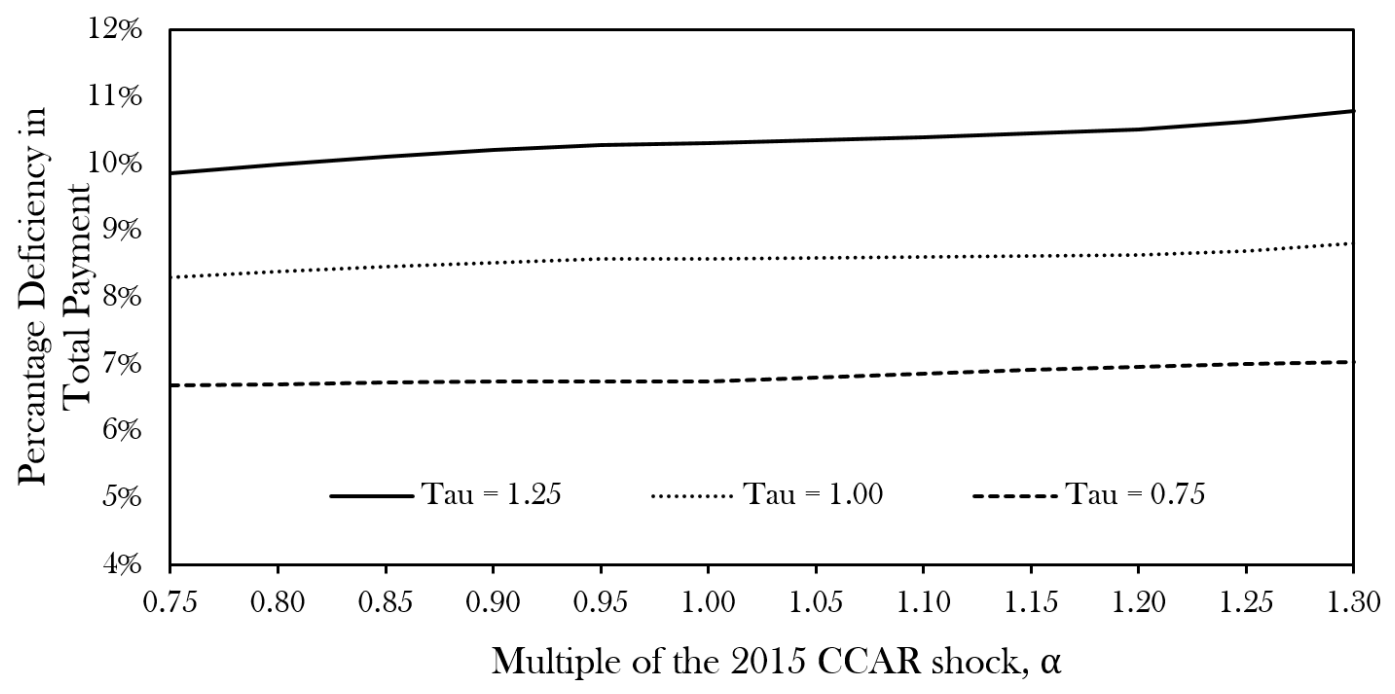

Source: Authors' calculations which use data provided to the OFR by The Depository Trust \& Clearing Corporation and Markit Group Ltd.

Figure 4: Impact on CCP for different values of $\tau$ and $\alpha$, compared with Cover-2.

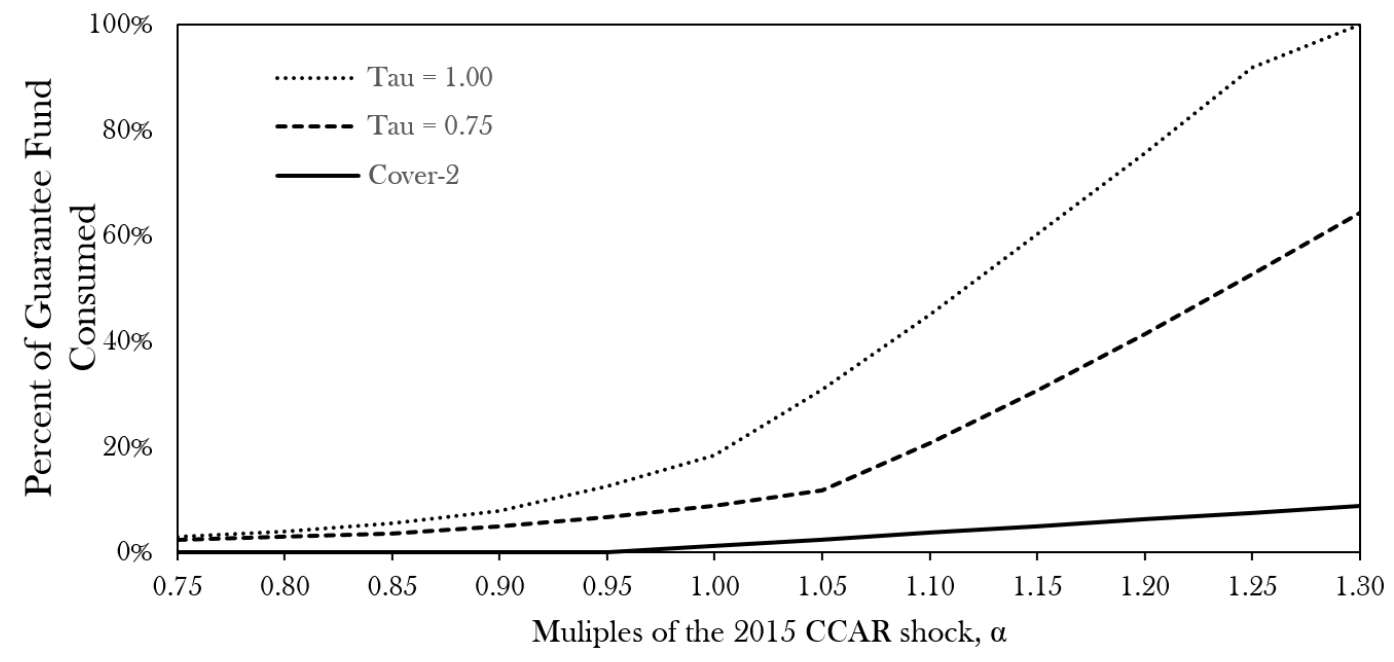

Source: Authors' calculations, which use data provided to the OFR by The Depository Trust \& Clearing Corporation and Markit Group Ltd.

\section{Evaluating the effect of member defaults from other causes}

Our analysis thus far is based solely on payment obligations arising from CDS contracts, and neglects the possibility that, in a severe financial crisis, member firms might default due to stresses on other parts of their balance sheets. In this section we consider the effects of such exogenous 
failures without attempting to model their causes explicitly. Instead we shall ask how many additional defaults by member firms (due to insolvency) would cause the CCP to default given that it may already be under stress due to CDS payment delinquencies by some of its members.

Fix a shock size $\alpha$ and transmission factor $\tau=1$. For each integer $k=0,1,2$, 3, or 4 , draw $k$ firms at random from the 15 BHC member firms, and assume that these firms fail due to unmodelled exogenous causes. For each such draw we compute the greatest payment equilibrium under the assumption that these $k$ firms default completely on their VM payments, while all other firms have a transmission factor $\tau=1$. If the CCP's guarantee fund, paid-in capital, and assessments of nondefaulting members are insufficient to meet its payment obligations, we say that the CCP 'defaults' for this random draw. We then count the proportion of $\left(\begin{array}{c}15 \\ k\end{array}\right)$ draws in which the CCP defaults, which yields the curve $h_{k}(\alpha)$ shown in Figure 5 . The function $h_{k}(\alpha)$ can be interpreted as the conditional default probability of the CCP given the exogenous failure of exactly $k$ of its members, where all such failures are assumed to be equally likely a priori but not necessarily independent.

Figure 5 shows that when the scale of the shock is less than 1.05, the CCP does not default even when four of its members fail exogenously. For larger shocks, however, exogenous member failures can push the CCP into default. Although we do not know how likely such failures are in absolute terms, we can estimate the probability that the CCP defaults relative to the failure probability of an average member using the following argument.

Fix a value of $\alpha$ (the scale of the shock), and let $q_{k}(\alpha)$ be the probability that exactly $k$ out of the 15 members fail under a shock of this magnitude. As above let $h_{k}(\alpha)$ be the conditional probability that the CCP defaults given the default of $k$ members drawn at random, where all such draws are assumed to be equally likely. The average probability that a given member defaults can be expressed as follows:

$$
p(\alpha)=\sum_{k=0}^{15} k q_{k}(\alpha) / 15 .
$$

The probability that the CCP defaults is

$$
q(\alpha)=\sum_{k=0}^{15} h_{k}(\alpha) q_{k}(\alpha) / 15 .
$$


Figure 5: Conditional Probability of CCP Default when $\tau=1$.

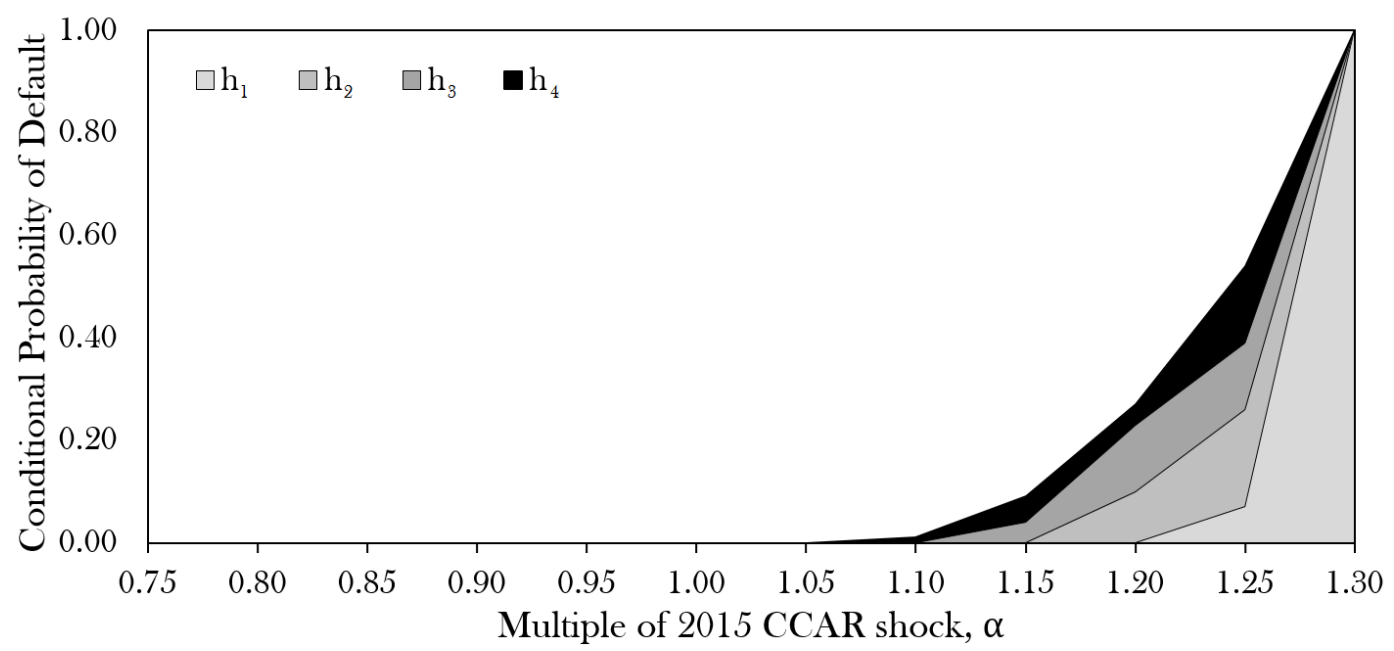

Note: Conditional probability of the CCP suffering a default given the default of one, two, three, or four BHC members, assuming the transmission factor $\tau=1$.

Source: Authors' calculations, which use data provided to the OFR by The Depository Trust \& Clearing Corporation and Markit Group Ltd.

Note that expressions (23) and (24) are very general and hold even when member failures are not independently distributed.

We shall now show how to bound the ratio $q(\alpha) / p(\alpha)$ from above and below under mild restrictions on the probabilities $q_{k}(\alpha)$. In particular, let us assume that the values $q_{k}(\alpha)$ are nonincreasing in $k$, and for all sufficiently large $k(k \geq \bar{k}), q_{k}(\alpha)$ is effectively zero. To bound $q(\alpha) / p(\alpha)$ from below we solve the optimization problem

$$
\min q(\alpha) / p(\alpha)=\frac{\sum_{k=0}^{15} h_{k}(\alpha) q_{k}(\alpha)}{(1 / 15) \sum_{k=0}^{15} k q_{k}(\alpha)}
$$

subject to

$$
\begin{array}{r}
1 \geq q_{0}(\alpha) \geq \ldots \geq q_{15}(\alpha) \geq 0 \\
\forall k \geq \bar{k}, q_{k}(\alpha)=0
\end{array}
$$

An upper bound on $q(\alpha) / p(\alpha)$ is found by solving the corresponding maximum problem. To illustrate the approach in a concrete case, let $\alpha=1.25$ (which we omit from the notation below). 
The conditional default probabilities are

$$
h_{0}=0.00, \quad h_{1}=0.07, \quad h_{2}=0.26, \quad h_{3}=0.39, \quad h_{4}=0.54 \text {. }
$$

Let us further assume that $q_{k}(\alpha)=0$ for all $k \geq \bar{k}=4 \sqrt[10]{10}$ By solving the corresponding optimization problem in (25) - 26) we find that $q / p$ satisfies the bounds

$$
1.05 \leq q / p \leq 1.89
$$

These bounds are not particularly sensitive to the cut-off value $\bar{k}$. For example, suppose that $q_{k}(\alpha)=0$ for all $k \geq 5$. It can be shown that in this case $q(\alpha) / p(\alpha)$ satisfies precisely the same bounds as in (28). If we assume that $q_{k}(\alpha)=0$ for all $k \geq 6$, we obtain the bounds $1.05 \leq q / p \leq 2.11$.

Table 5 shows the estimated bounds for $q / p$ under different combinations of $\tau$ and $\alpha$, assuming that $q_{k}(\alpha)=0$ for all $k \geq 4$. When $\tau \leq 1$ and $\alpha \leq 1$, the CCP is unlikely to default although it may have to access a major part of its guarantee fund to cover its obligations. If the shock is somewhat larger than the CCAR shock $(\alpha \geq 1.25)$ and if $\tau \geq 1.25$, the CCP would be at greater risk of defaulting than the average member firm.

Table 5: Estimated Upper and Lower Bounds on $q(\alpha) / p(\alpha)$

\begin{tabular}{c|c|ccc}
\hline \hline \multicolumn{2}{c}{} & \multicolumn{3}{c}{$\alpha$} \\
\cline { 3 - 5 } \multicolumn{2}{c}{} & $\mathbf{0 . 7 5}$ & $\mathbf{1 . 0 0}$ & $\mathbf{1 . 2 5}$ \\
\hline \multirow{\tau}{*}{$\tau$} & $\mathbf{0 . 7 5}$ & 0.0 & 0.0 & $0.0-0.3$ \\
& $\mathbf{1 . 0 0}$ & 0.0 & 0.0 & $1.1-1.9$ \\
& $\mathbf{1 . 2 5}$ & $0.0-0.3$ & $7.5-15$ & $7.5-15$ \\
\hline
\end{tabular}

Source: Authors' calculations, which use data provided to the OFR by The Depository Trust \& Clearing Corporation and Markit Group Ltd.

\section{Conclusion}

In this paper we have proposed a general framework for assessing the ability of a derivatives central counterparty (CCP) to withstand a severe credit shock. The framework differs from conven-

\footnotetext{
${ }^{10}$ In fact the U.S. authorities did not allow more than two large institutions (Lehman and Bear Stearns) to default during the recent financial crisis. The market implied default rates during the crisis also assigned a very low probability to four or more defaults (Giglio (2011)).
} 
tional stress testing of CCPs in several key respects. First, we track the direct and indirect effects of default by one or more firms, not just the default of the two members with the largest obligations to the CCP. This is crucial because payment deficiencies by defaulting firms are transmitted and amplified through the network of exposures, increasing the ultimate impact on the CCP. Secondly, we propose a novel estimation methodology that allows us to place a lower bound on the amount of network contagion in the absence of detailed information about the liquid reserves of individual firms. In this respect the model differs markedly from conventional contagion models such as Eisenberg and Noe, which require detailed knowledge of the firms' balance sheets to determine the impact of a shock. Thirdly, we show how to estimate upper and lower bounds on the default probability of the CCP relative to the default probability of its members, given minimal information about the degree of correlation among member defaults.

Overall, our results suggest that conventional stress testing approaches may significantly underestimate the vulnerability of the main CCP for this market. Moreover, our results do not include several channels that could further increase the amount of contagion and the concomitant risk of CCP default. One such channel is increased demand for initial margin in times of financial stress, when firms call on their counterparties to increase the amount of initial margin they post. These demands have the effect of placing the counterparties under even greater stress. A second channel consists of single-name CDS contracts in which the reference entity is a bank holding company (BHC). The stress induced by demands for large variation margin payments may push some of these BHCs closer to (or into) default, which will trigger large variation margin payments by the sellers of CDS on these companies. A third channel is elevated replacement cost: when a seller of protection defaults on its variation margin payments, the counterparty will try to find another (solvent) firm that is willing to assume the position of protection seller. This pressure to find replacements will tend to increase the cost of novating the contracts, and may lead to potential losses that are not covered by the defaulting party's initial margin. Finally, there are spillover effects between CCPs that arise from common members and cross-margin agreements (Cont (2010), Barker et al. (2016)), which we have not included due to data limitations. All of these factors will tend to exacerbate the amount of contagion in the system, hence the preceding results should be viewed as a conservative estimate of the potential vulnerability of the CCP due to network effects. 


\section{References}

Barker, R., Dickinson, A., Lipton, A., and Virmani, R. (2016). Systemic risks in CCP networks. arXiv preprint arXiv:1604.00254.

BCBS and IOSCO (2015). Margin requirements for non-centrally-cleared derivatives. Technical report, BIS and OICU-IOSCO, Basil, Switzerland.

Calomiris, C. W. (2009). The subprime turmoil: What's old, what's new, and what's next. The Journal of Structured Finance, 15(1):6-52.

Campbell, S. D. and Ivanov, I. (2016). Empirically evaluating systemic risks in CCPs: The case of two CDS CCPs. Available at SSRN: https://ssrn.com/abstract=2841076.

CFTC (2016). Supervisory stress test of clearinghouses. A report by staff of the U.S. Commodity Futures Trading Commission. Washington, DC.

Cont, R. (2010). Credit default swaps and financial stability. Financial Stability Review, 14:35-43.

Cont, R. and Kokholm, T. (2014). Central clearing of OTC derivatives: Bilateral vs multilateral netting. Statistics \& Risk Modeling, 31(1):3-22.

Cont, R. and Minca, A. (2016). Credit default swaps and systemic risk. Annals of Operations Research, 247(2):523-547.

Cumming, F. and Noss, J. (2013). Assessing the adequacy of CCPs default resources. Bank of England Financial Stability Paper 26.

Domanski, D., Gambacorta, L., and Picillo, C. (2015). Central clearing: Trends and current issues. BIS Quarterly Review.

Duffie, D., Scheicher, M., and Vuillemey, G. (2015). Central clearing and collateral demand. Journal of Financial Economics, 116(2):237-256.

Eisenberg, L. and Noe, T. (2001). Systemic risk in financial systems. Management Science, $47(2): 236-249$.

Evanoff, D. D., Russo, D., Steigerwald, R., et al. (2006). Policymakers, researchers, and practitioners discuss the role of central counterparties. Economic Perspectives, (Q IV):2-21. 
Federal Reserve Board (2016). Stress tests and capital planning: Comprehensive capital analysis and review. Technical report, Board of Governors of the Federal Reserve System, Washington, DC.

France, V. G. and Kahn, C. M. (2016). Law as a constraint on bailouts: Emergency support for central counterparties. Journal of Financial Intermediation, 28:22-31.

Garratt, R. and Zimmerman, P. (2015). Does central clearing reduce counterparty risk in realistic financial networks? Staff Report, Federal Reserve Bank of New York 717.

Garratt, R. and Zimmerman, P. (2017). Centralized netting in financial networks. Journal of Banking $\&$ Finance.

Ghamami, S. and Glasserman, P. (2017). Does OTC derivatives reform incentivize central clearing? Journal of Financial Intermediation, 32:76-87.

Giglio, S. (2011). Credit default swap spreads and systemic financial risk. Proceedings, Federal Reserve Bank of Chicago, 10(9):104-141.

Glasserman, P. and Young, H. P. (2015). How likely is contagion in financial networks? Journal of Banking \& Finance, 50:383-399.

Heath, A., Kelly, G., and Manning, M. (2015). Central counterparty loss allocation and transmission of financial stress. Reserve Bank of Australia Research Discussion Paper 2015-02.

Heath, A., Kelly, G., Manning, M., Markose, S., and Shaghaghi, A. R. (2016). CCPs and network stability in OTC derivatives markets. Journal of Financial Stability, 27:217-233.

Luo, L. S. (2005). Bootstrapping default probability curves. Journal of Credit Risk, 1(4):169-179.

Nahai-Williamson, P., Ota, T., Vital, M., and Wetherilt, A. (2013). Central counterparties and their financial resources-a numerical approach. Bank of England Financial Stability Paper 19.

Paddrik, M., Rajan, S., and Young, H. P. (2019). Contagion in derivatives markets. Management Science. forthcoming.

Pirrong, C. (2014). A bill of goods: Central counterparties and systemic risk. Journal of Financial Market Infrastructures, 2(4):55-85.

Poce, G., Cimini, G., Gabrielli, A., Zaccaria, A., Baldacci, G., Polito, M., Rizzo, M., and Sabatini, S. (2016). What do central counterparties default funds really cover? a network-based stress test answer. arXiv preprint arXiv:1611.03782. 
Powell, J. H. (2016). A financial system perspective on central clearing of derivatives. In The New International Financial System: Analyzing the Cumulative Impact of Regulatory Reform, pages 47-59. World Scientific.

Tarski, A. (1955). A lattice-theoretical fixpoint theorem and its applications. Pacific Journal of Mathematics, 5(2):285-309.

Zigrand, J.-P. (2010). What do network theory and endogenous risk theory have to say about the effects of central counterparties on systemic stability? Financial Stability Review, 14:153-158. 